JOURNAL OF BIOLOGICAL ENGINEERING

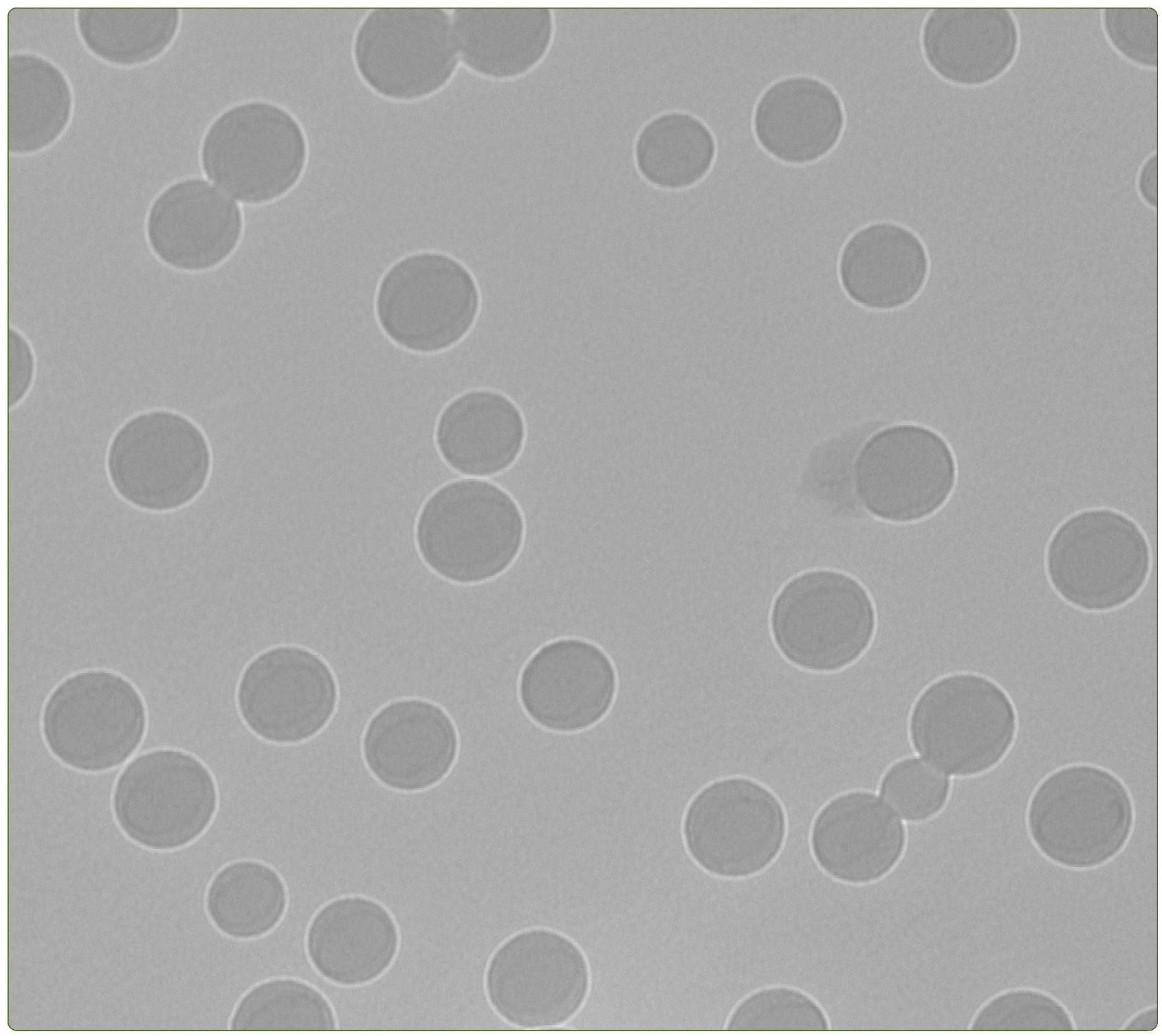

\title{
Bioresponsive matrices in drug delivery
}

You et al. 


\title{
Bioresponsive matrices in drug delivery
}

Jin-Oh You, Dariela Almeda, George JC Ye, Debra T Auguste*

\begin{abstract}
For years, the field of drug delivery has focused on (1) controlling the release of a therapeutic and (2) targeting the therapeutic to a specific cell type. These research endeavors have concentrated mainly on the development of new degradable polymers and molecule-labeled drug delivery vehicles. Recent interest in biomaterials that respond to their environment have opened new methods to trigger the release of drugs and localize the therapeutic within a particular site. These novel biomaterials, usually termed "smart" or "intelligent", are able to deliver a therapeutic agent based on either environmental cues or a remote stimulus. Stimuli-responsive materials could potentially elicit a therapeutically effective dose without adverse side effects. Polymers responding to different stimuli, such as pH, light, temperature, ultrasound, magnetism, or biomolecules have been investigated as potential drug delivery vehicles. This review describes the most recent advances in "smart" drug delivery systems that respond to one or multiple stimuli.
\end{abstract}

\section{Introduction}

Polymeric materials that respond to a stimulus are often called "smart" or "intelligent" due to their intrinsic ability to alter their physical or chemical properties. For the majority of the polymers that fall into this category, the response to a change in the surrounding environment is not only quick, on the order of minutes $[1,2]$ to hours $[3,4]$, but also reversible, mimicking the dynamics observed in natural polymers, such as proteins, polysaccharides, and nucleic acids in living organic systems [5]. The response to stimuli is manifested in many forms: individual chain dimension/size, shape, surface characteristics, secondary structure, solubility, and degree of intermolecular association. These unique capabilities have been applied to a diverse range of applications, including: drug delivery $[4,6-8]$, diagnostics $[9,10]$, biological coating technologies [11,12], biosensing [10,13], and microfluidics [14].

Conventional drug delivery methods physically entrap molecules within a polymer lattice; drug is released slowly by diffusion or upon degradation of the network. These methods typically result in an early peak in plasma drug concentration followed by a steady, linear release. This is far from ideal because the local drug concentration and location of delivery is not precisely controlled. Below the therapeutic dose, the drug is ineffective whereas high concentrations of drug may be

\footnotetext{
* Correspondence: auguste@seas.harvard.edu

School of Engineering and Applied Sciences, Harvard University, Cambridge, MA 02138, USA
}

toxic or lead to undesirable side effects. Polymers have been used to tailor drug release, which maintains the drug concentration within the desired therapeutic range. However, such controlled release systems are insensitive to metabolic changes in the body and are unable to modulate drug release nor target the drug to diseased tissue. This lack of control has motivated the exploitation of bioresponsive polymers as drug carriers.

As early as the $1950 \mathrm{~s}$, stimuli responsive hydrogels have been studied for drug release [15]. Since then, polymers that react to different stimuli have been developed. These stimuli include $\mathrm{pH}$ [16-20], ionic strength [21], and the presence of metabolic chemicals (e.g., enzymes or antigens) $[22,23]$. Such stimuli may enable a drug carrier to distinguish between diseased and healthy tissue. More recently, drug carriers that respond to magnetic fields [24], light [25], radiation [26], and ultrasound [27] have also been developed. These external stimuli allow for greater control over when and where the drug is released. By tuning the formulation or chemical moieties of the polymer, the sensitivity to the stimuli can be precisely controlled. This review aims to provide an overview of how responsive polymers may be used to improve drug delivery.

\section{Stimuli-responsive materials for drug delivery $\mathrm{pH}$-sensitive drug delivery}

$\mathrm{pH}$-sensitive polymers (see Table 1 ) have garnered much attention in the fields of drug delivery $[28,29]$, gene 
Table 1 Stimuli-sensitive drug delivery.

\begin{tabular}{|c|c|c|c|}
\hline Stimulus & Carrier type & Payload & Reference \\
\hline \multirow[t]{3}{*}{$\mathrm{pH}$} & PPADK & Dexamethasone & {$[45]$} \\
\hline & DMAEMA/HEMA & Paclitaxel & [3] \\
\hline & PC/DAP liposomes & SiRNA & {$[51]$} \\
\hline \multirow[t]{3}{*}{ Temperature } & PNIPAm/PLGA & Paclitaxel & {$[36]$} \\
\hline & MPPC/DPPC/HSPC/DSPEC-PEG-2000 & Doxorubicin & {$[54]$} \\
\hline & FA/PDMA/PNIPAm & Dipyridamole & {$[57]$} \\
\hline \multirow[t]{3}{*}{ Light } & Cu chlorophyllin/PNIPAm & None reported & {$[60]$} \\
\hline & Quinone-methide & Nile Red & [63] \\
\hline & $\mathrm{Au} / \mathrm{meso}$ porous silica & Paclitaxel & [61] \\
\hline \multirow[t]{2}{*}{ Ultrasound } & Pluronic P105/N,N-diethylacrylamide & Doxorubicin & {$[66]$} \\
\hline & DPPC:DPPE-PEG2000 liposomes & Calcein & {$[67]$} \\
\hline \multirow[t]{2}{*}{ Glucose } & $\begin{array}{l}\text { poly(methacrylic acid-g-ethylene glycol) with glucose oxidase, PNIPAm with } \\
\text { phenylboronic acid }\end{array}$ & Insulin & [69-72] \\
\hline & PNIPAm or carboxymethyl dextran with con. A & None reported & {$[73,74]$} \\
\hline \multirow[t]{3}{*}{ Enzyme } & PEG diacrylate/human neutrophil elastase-sensitive peptide & None reported & {$[75]$} \\
\hline & Fibrin/ $\beta$-nerve growth factor fusion proteins & $\beta$-nerve growth factor & {$[76]$} \\
\hline & 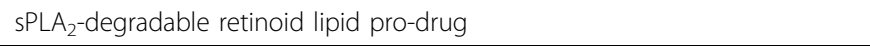 & Retinoid lipid pro-drug & {$[77]$} \\
\hline \multirow[t]{4}{*}{ Magnetic } & Magnetite & $\begin{array}{l}\text { Squalenoyl gemcitabine } \\
\text { (SQdFdC) }\end{array}$ & {$[78]$} \\
\hline & Poly[aniline-co-N-(1-one-butyric acid)] aniline (SPAnH)/iron oxide & Epirubicin & {$[79]$} \\
\hline & Polylactide/nanocrystalline magnetite & Paclitaxel & [80] \\
\hline & Egg-PC/maghemite/PAH/PSS & Calcein & [81] \\
\hline
\end{tabular}

delivery [30], and insulin delivery [31]. Generally, $\mathrm{pH}$-sensitive polymers have weak acids or bases with $p \mathrm{~K}_{\mathrm{a}}$ values between 3 and 10 [32]. Carboxylic, sulfonate, and primary or tertiary amino groups exhibit a change in ionization state as a function of $\mathrm{pH}$. Transitions in solubility, conformation, and swelling arise due to changes in ionization, where specific polymer groups switch between a neutral and charged state (e.g., poly $(\mathrm{N}$, $\mathrm{N}$-dimethylaminoethyl methacrylate (DMAEMA) [33-35]) or a hydrophilic and hydrophobic state (e.g., poly( $N$-iso-propylacrylamide) (PNIPAm) [36-38]).

Eisenberg et al. investigated $\mathrm{pH}$-sensitive polymer swelling to control the release of drug molecules [15]. Since then, several biocompatible and biodegradable $\mathrm{pH}$-sensitive polymers have been developed. Unfortunately, few $\mathrm{pH}$-sensitive polymers have been used for drug delivery systems because of their limited sensitivity near the $\mathrm{pH}$ of blood ( $\mathrm{pH}$ 7.4). For example, natural polymers (alginate $[39,40]$, chitosan $[41,42]$, and carrageenan [43]) and synthesized polymers (poly(acrylic acid) (AA) [44] and poly(methacrylic acid) (MAA) [45]) exhibit a high swelling property at high $\mathrm{pH}$ due to ionizable functional groups on the polymer backbone or side chain. These polymers are not responsive under most physiological conditions, albeit the gastrointestinal system.
Systemic delivery requires that drug carriers respond to small changes in $\mathrm{pH}$, near $\mathrm{pH}$ 7.4. In 2005, Heffernan and Murthy developed an acid-sensitive biodegradable drug delivery vehicle using poly $(1,4$-phenyleneacetone dimethylene ketal) (PPADK), which contains ketal linkages allowing for acid-catalyzed hydrolysis of the polymer into low molecular weight hydrophilic compounds. Thus, the release of drug molecules is accelerated under acidic conditions [46]. You and Auguste synthesized a series of $\mathrm{pH}$-sensitive nanoparticles comprised of DMAEMA and 2-hydroxyethyl methacrylate (HEMA) (Figure 1) [3]. DMAEMA is a pH-responsive monomer that has a tertiary amine functional group with a $p \mathrm{~K}_{\mathrm{a}}$ of 7.5 [47]. In vitro results support that the drug would remain within the particle during circulation; upon exposure to a low $\mathrm{pH}$ environment (e.g., a tumor [48]), the particle would swell resulting in release of the drug. Monodisperse, $\mathrm{pH}$-sensitive DMAEMA/HEMA nanocarriers encapsulating paclitaxel exhibited $\mathrm{pH}$-dependent release kinetics (Figure 2). The particles had a high volume swelling ratio at low $\mathrm{pH}$, low crosslinking density, and high content of DMAEMA. A similar series of particles were used for gene delivery, where triggered release of plasmid DNA within the low $\mathrm{pH}$ endosome was optimized $[49,50]$. Plasmid DNA for green fluorescent protein was encapsulated. HeLa cells were successfully 


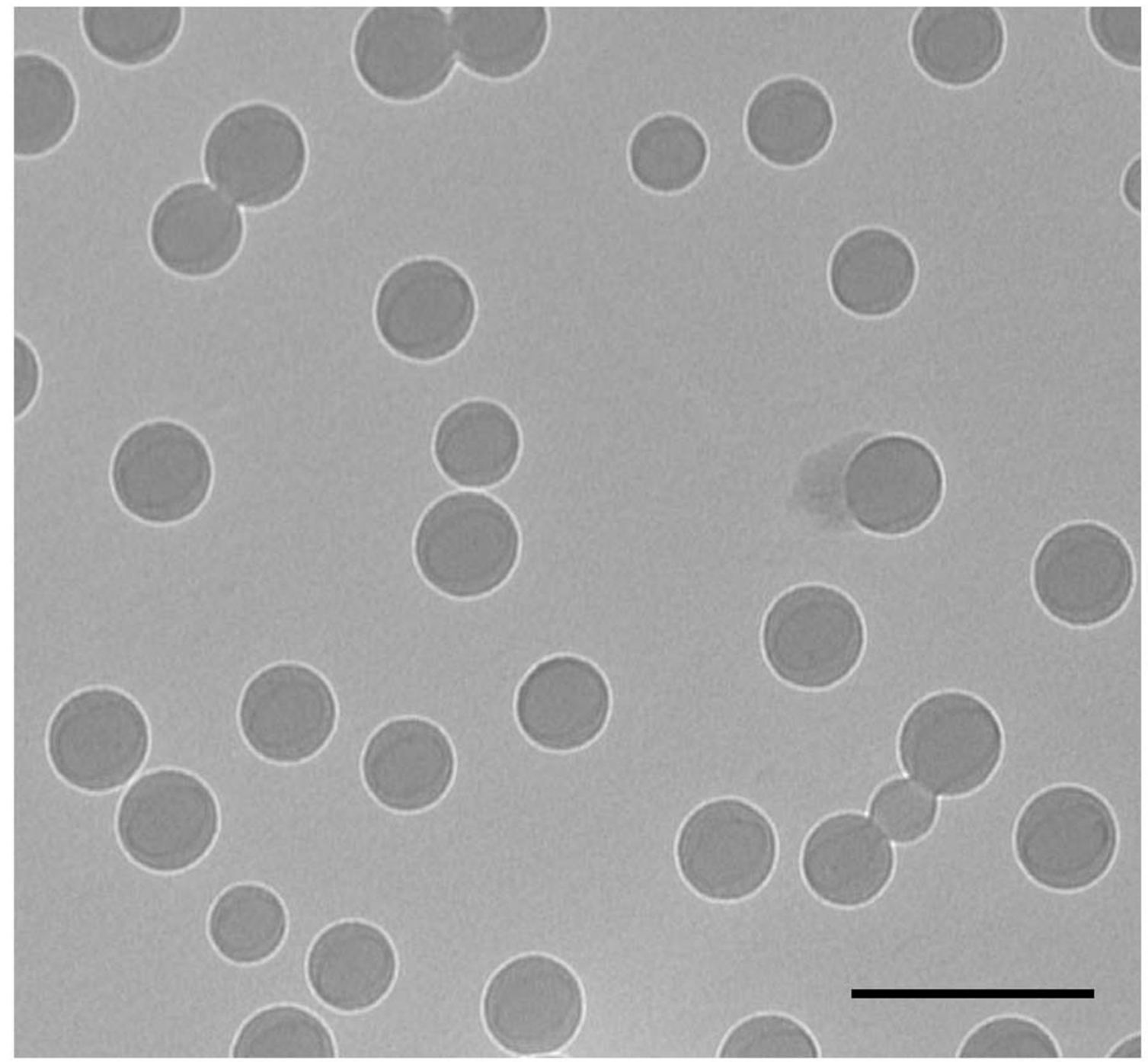

Figure 1 Transmission electron microscope image of DMAEMA/HEMA nanoparticles used for drug delivery. Scale bar is $500 \mathrm{~nm}$ [3].

transfected with a dependence on the swelling ratio and crosslinking density (Figure 3 ).

$\mathrm{pH}$-dependent liposomes have also been used to trigger the release of drug within acidic environments. Auguste et al. formulated liposomes with variable surface charge by varying the lipid composition [51]. pHsensitive liposomes were composed of a zwitterionic lipid (phosphatidylcholine) and a titratable lipid (dimethylammonium propane) with a $p \mathrm{~K}_{\mathrm{a}}$ of 6.7. This allowed the liposome's net charge to become cationic upon decreasing the $\mathrm{pH}$. $\mathrm{pH}$-dependent liposomes may be shielded from the immune system using poly(ethylene glycol) (PEG)-b-polycation polymers. The polycation block electrostatically anchored the PEG polymer to the liposome surface at $\mathrm{pH} 7.4$, but released the polymer at $\mathrm{pH} 5.5$ due to electrostatic repulsion between the cationic polymer and cationic liposome surface. The triggered release of adsorbed PEG-b-polycation polymers from $\mathrm{pH}$-dependent liposomes may protect the drug carrier from immune recognition during circulation ( $\mathrm{pH} 7.4)$ and allow subsequent intracellular delivery of siRNA within the endosome. The bare liposome maintains the membrane disruption/fusion capability [52,53].

\section{Temperature-sensitive drug delivery}

Increases in temperature are associated with several disease states (e.g., cancer [54,55]). Thermo-responsive drug carriers have been employed to release their payload within environments above the physiological 


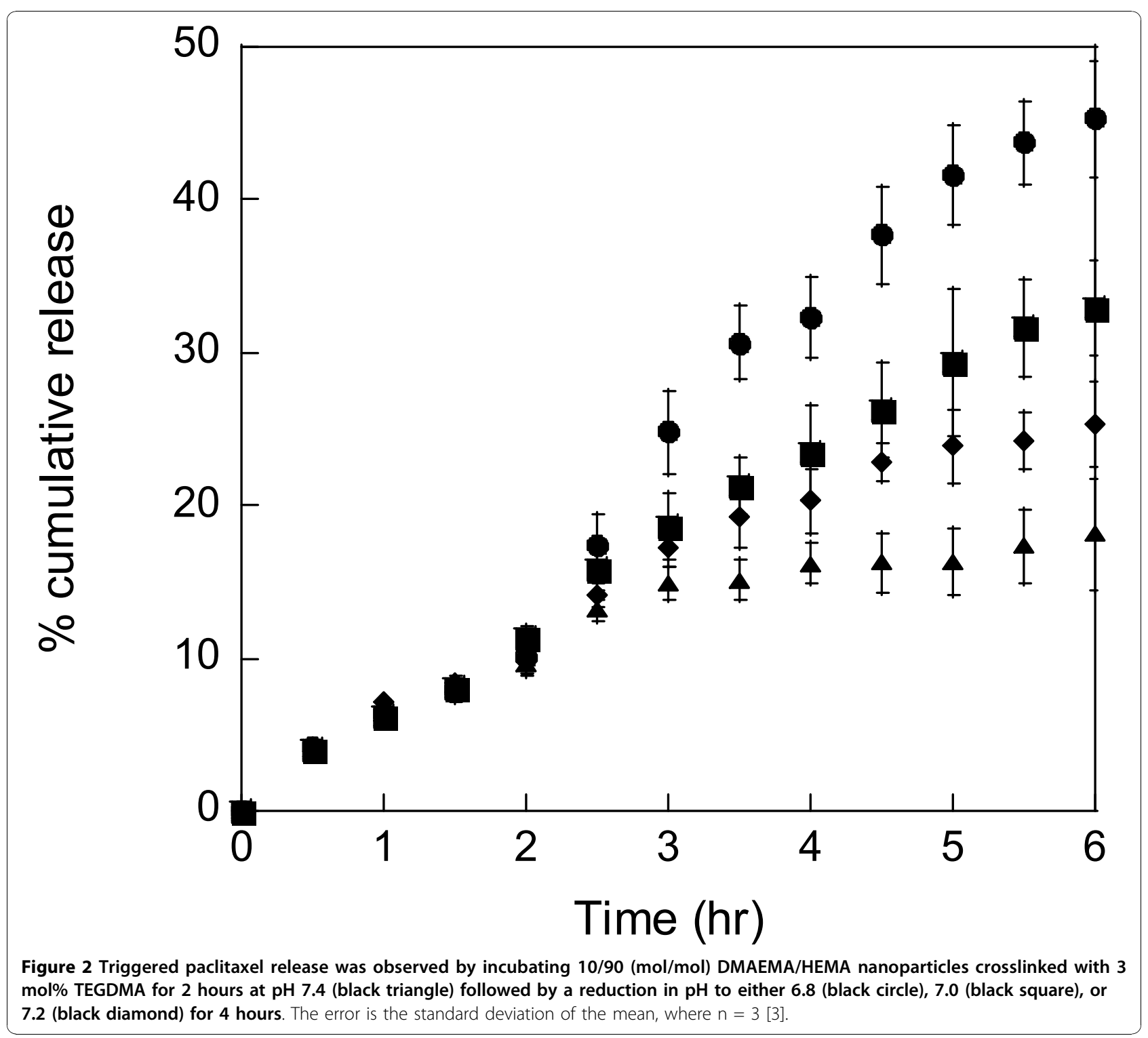

temperature. Thermo-sensitive polymers exhibit a phase transition in solution at a temperature known as the lower critical solution temperature (LCST). For example, PNIPAm, a well-studied thermo-responsive polymer, undergoes a reversible phase transition in aqueous solution from hydrophilic to hydrophobic at its LCST of approximately $32^{\circ} \mathrm{C}$. Chemical modifications of PNIPAm have been effective in controlling the LCST [56]. In 2005 , Liu et al. synthesized poly $(N$-isopropylacrylamide$c o-\mathrm{N}, \mathrm{N}$-dimethylacrylamide)- $b$-poly(D,L-lactide- $c o$-glycolide) micelles for controlled paclitaxel delivery [36]. Paclitaxel release was accelerated when the physiological temperature was raised above the LCST. The paclitaxelloaded micelles were more effective in killing human breast carcinoma cells at $39.5^{\circ} \mathrm{C}$ than $37^{\circ} \mathrm{C}$. De and colleagues developed folate-conjugated, thermo-responsive block copolymer micelles. Folate is known to bind to several cancer cell types [57]. The drug release studies from folate-conjugated PNIPAm-DMA micelles demonstrated a temperature-responsive drug release. Delivery of paclitaxel at the tumor site can alter the overall drug biodistribution. Needham et al. developed temperaturesensitive liposomes containing doxorubicin [54]. Their liposome formulation, composed of 1-palmitoyl-2hydroxy-sn-glycero-3-phosphocholine (MPPC), 1,2dipalmitoyl-sn-glycero-3-phosphocholine (DPPC), hydrogenated soy $s n$-glycero-3-phosphocholine (HSPC), and 1,2-distearoyl-sn-glycero-3-phosphoethanolamine- $N$ polyethylene glycol 2000 (DSPE-PEG-2000), was optimized to rapidly release the drug under mild hyperthermic temperatures $\left(39^{\circ} \mathrm{C}\right.$ to $\left.40^{\circ} \mathrm{C}\right)$. Changing the drug biodistribution can increase therapeutic efficacy. 


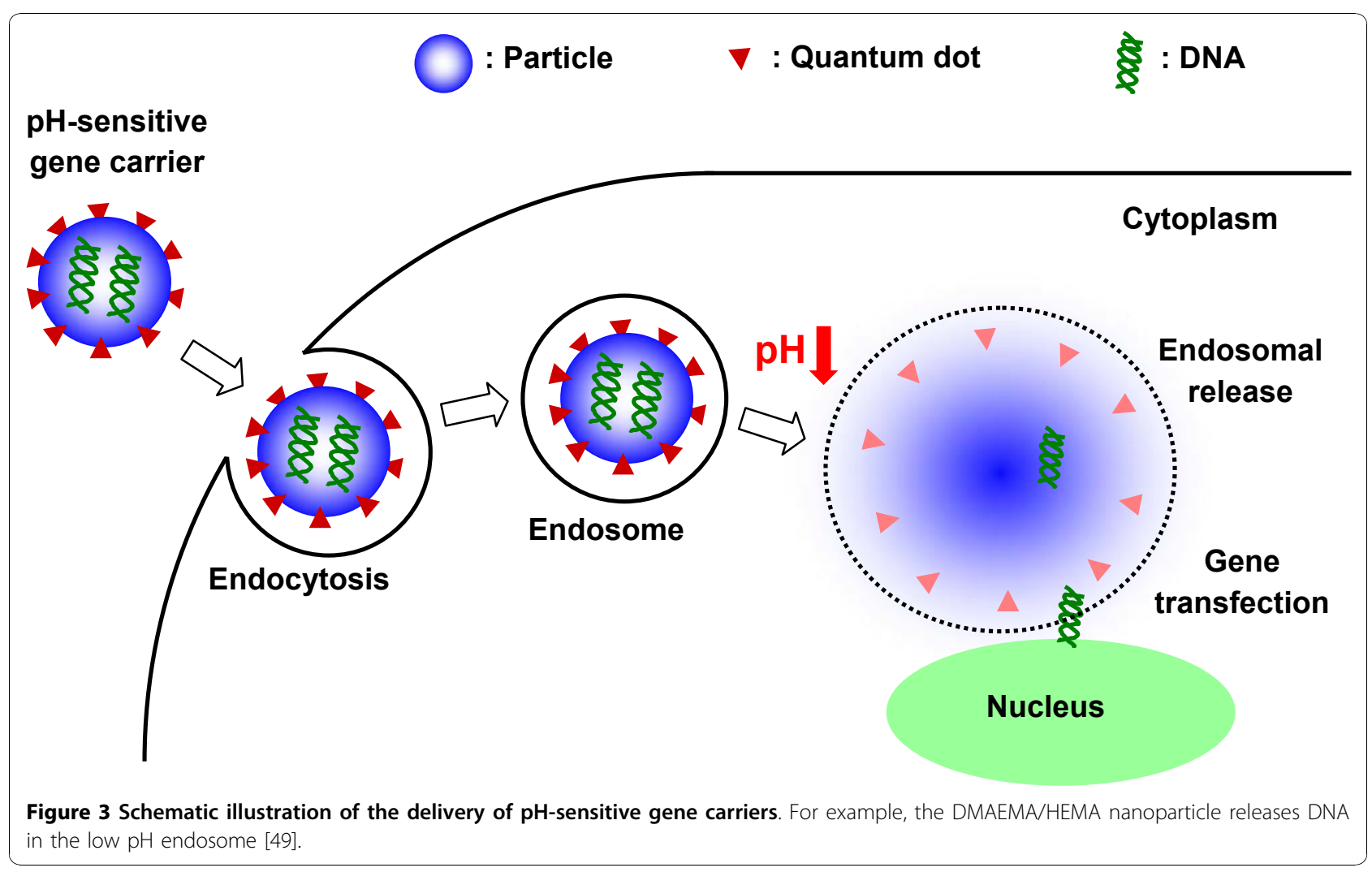

\section{Light-sensitive drug delivery}

Light (ultraviolet or visible) is a desirable external stimulus for drug delivery systems because it is inexpensive and easily controlled. Light-sensitive drug carriers are fabricated from polymers that contain photo-sensitizers such as azobenzene, stilbene, and triphenylmethane $[37,58,59]$. Suzuki and Tanaka have investigated visible light-responsive hydrogels using the trisodium salt of copper chlorophyllin in PNIPAm hydrogels [60]. When light is applied to the hydrogels, the chromophore absorbs the light, increasing the local temperature of the hydrogel. The resulting temperature change alters the swelling behavior. Vivero-Escoto et al. prepared goldcapped mesoporous silica nanospheres for photoinduced intracellular release of drugs in human cells [61]. The $100 \mathrm{~nm}$ silica nanospheres were capped with 5 $\mathrm{nm}$ gold nanospheres and functionalized with a cationic photo-reactive linker. Photoirradiation using ultraviolet (UV) light for $10 \mathrm{~min}$ at $0.49 \mathrm{~mW} / \mathrm{cm}^{2}$ cleaved the photolabile linker, causing uncapping of the silica due to charge repulsion between the gold and silica nanospheres, allowing drug to be released [61,62]. Fomina et al. developed a novel light-sensitive polymer containing a quinone-methide moiety [63]. Nile Red, a hydrophobic dye, was released from nanoparticles after only one minute of $350 \mathrm{~nm}$ light exposure. Light can be effective in modulating drug release because it can be used to increase the local temperature and to cleave bonds.

\section{Ultrasound-sensitive drug delivery}

Ultrasound has been shown to trigger drug release by raising the local temperature or causing cavitation [64]. Both processes can increase the permeability of cell membranes and accelerate polymer degradation [65]. Ultrasound-sensitive vehicles have the potential to treat tumorigenic cancers due to their invasive character, ability to penetrate deeply into the human body, and ease of control. In 2002, Pruitt and Pitt investigated ultrasoundmediated doxorubicin release using stabilized Pluronic P105 micelles [66]. Doxorubicin was encapsulated within polymeric micelles composed of $10 \%$ Pluronic P105 and N,N-diethylacrylamide and delivered systemically to rats. Application of low-frequency ultrasound at the tumor site resulted in doxorubicin release; this resulted in a significant reduction in tumor volume. Lin et al. have investigated the physical and chemical properties of lipid membranes subjected to ultrasound treatment [67]. They showed that high permeability resulting from ultrasound treatment is correlated with lipid packing and can be useful for efficient drug release and ultrasound-mediated DNA transfection. In 2007, Ferrara et al. reviewed that small gas bubbles, used to enhance 
ultrasound contrast, can be used for drug delivery applications and monitoring [68]. When driven by an ultrasonic pulse, small gas bubbles oscillate with a wall velocity on the order of tens to hundreds of meters per second and can be deflected to a vessel wall or fragmented into particles on the order of nanometers. Also, a focused ultrasound beam can be used for disruption of delivery vesicles and blood vessel walls, which offer the opportunity to locally deliver a drug or gene. Ultrasound does not damage the surrounding tissue, making it attractive for triggering drug release.

\section{Biomolecule-responsive drug delivery}

The presence of biomolecules specific to an organ or disease state may be useful to regulate the release of drugs. Biomolecules can either participate in a chemical reaction or result in cleavage of a chemical bond. In this section, we will discuss the use of hydrogels that are (1) responsive to glucose and (2) use enzymes to facilitate hydrogel degradation.

Glucose-responsive hydrogels have been investigated for self-regulating the release of insulin for the treatment of diabetes. Early studies have been largely based on the combination of glucose oxidase with polyelectrolyte hydrogels that exhibit $\mathrm{pH}$-responsive swelling or shrinking behavior $[69,70]$. As glucose diffuses within the hydrogel, entrapped glucose oxidase catalyzes its conversion to gluconic acid, lowering the local $\mathrm{pH}$ of the gel and resulting in swelling and the subsequent release of insulin. However, the efficiency of glucose oxidase decreases with $\mathrm{pH}$. PNIPAm coupled with phenylboronic acid has been investigated as a glucoseresponsive system [71,72]. Introduction of phenylboronic acid decreases the volume phase transition temperature. The hydrogel swells in the presence of glucose. More recently, Miyata et al. demonstrated that biomolecular complexes such as the carbohydrate-binding lectin, concanavalin A (Con. A), could be coupled with PNIPAm to achieve reversible swelling or shrinking in response to stepwise changes in glucose concentration [73]. Zhang et al. also utilized Con. A as the cross-linker for carboxymethyl dextran (CM-dextran) based hydrogels. Competitive displacement between Con. A and terminal glucose moieties on dextran by free glucose changed both the morphology and permeability of the gel [74]. Although these systems triggered insulin release through volumetric changes, regulating the rate and reliability of release remains a challenge.

Researchers have also exploited the presence of site or disease specific enzymes in drug delivery by incorporating enzyme-cleavable peptides within hydrogels. For example, Aimetti et al. prepared a PEG hydrogel drug delivery system which incorporated human neutrophil elastase (HNE)-sensitive linkers for the treatment of inflammation. HNE is a serine protease secreted by neutrophils, which accumulates at sites of inflammation. HNE-sensitive peptides were synthesized using solid phase Fmoc chemistry and their degradation kinetics were characterized. The rate of substrate degradation can be tailored by the incorporation or substitution of specific amino acids. Local, controlled release from hydrogels containing HNE-sensitive peptides was achieved in the presence of HNE as visualized by fluorescence energy resonance transfer (FRET) [75].

Growth factor delivery, controlled by enzymes involved in tissue regeneration, has also been investigated. Sakiyama-Elbert et al. designed the delivery of beta-nerve growth factor ( $\beta$-NGF) from fibrin matrices as a nerve regeneration therapy. They synthesized $\beta$ NGF fusion proteins with an enzymatically degradable linker that served as the covalent anchor to the fibrin matrix and thus prevented a potential loss of enzymatic activity [76]. Researchers have also exploited the enzyme-triggered degradability of certain prodrugs. Pedersen et al. investigated anti-cancer retinoid lipophilic drugs that are covalently attached to phospholipids. These prodrugs have a lipid backbone that is degradable by secretory phospholipase $\mathrm{A}_{2}\left(\mathrm{sPLA}_{2}\right)$ IIA. The prodrugs self-assembled into liposomes, which were susceptible to degradation by $\left(\mathrm{sPLA}_{2}\right)$ IIA. In vitro studies utilizing MT-3 breast carcinoma and HT-29 colon adenocarcinoma cell lines demonstrated high cytotoxicity of prodrug liposomes only in the presence of the $\left(\mathrm{sPLA}_{2}\right)$ IIA enzyme [77].

\section{Magnetic-sensitive drug delivery}

Magnetic drug delivery systems possess three main advantages: (1) visualization of drug delivery vehicles, (2) ability to guide and control movement of drug carriers through magnetic fields, and (3) thermal heating which has been used to control drug release or produce tissue ablation. Magnetic drug carriers like magnetite, maghemite, cobalt ferrite, and carbonyl iron are biocompatible, non-toxic and non-immunogenic [78]. Arias et al. utilized magnetite to produce magnetic core/shell nanoparticles for drug delivery. The nanoparticles consisted of a magnetite core with a self-assembling squalenoyl gemcitabine, an amphiphilic anti-cancer drug, shell. Optical microscopy images showed the alignment of the core/shell nanoparticles under the influence of a $0.2 \mathrm{~T}$ magnetic field [78]. Liu et al. reported in vitro and in vivo studies of poly[aniline-co- $N$-(1-one-butyric acid)] aniline (SPAnH) nanoparticles encapsulating iron oxide $\left(\mathrm{Fe}_{3} \mathrm{O}_{4}\right)$. To overcome the blood-brain barrier, the authors utilized focused ultrasound to temporarily disrupt the barrier and increase permeability. Their results showed that an estimated $0.16 \pm 0.03 \mathrm{mM}$ of magnetic nanoparticles were delivered to brain tumors in 
Sprague-Dawley rats; this was estimated to be 15 -fold higher than the therapeutic range [79]. Magnetic nanoparticles have also been proposed as a component in drug eluting stents for the treatment of vascular diseases. Chorny et al. reported the use of polylactide nanoparticles incorporating magnetite nanocrystals and encapsulating paclitaxel. In vitro studies demonstrated cell growth inhibition with a relatively low dose and brief (five minute) magnetic field exposure. In vivo studies performed in a rat carotid artery model of stent restenosis showed a significant benefit over the control group. Additionally, $13.2 \pm 2.0 \mu \mathrm{g}$ of magnetic nanoparticles delivered to the stented carotid segment under a magnetic field were retained in the artery compared to only $3.4 \pm 1.9 \mu \mathrm{g}$ of particles delivered without a magnetic field [80].

Magnetic nanoparticles have also been encapsulated within liposomes. da Silva Gomes et al. synthesized liposomes encapsulating magnetic nanoparticles with an outer polyelectrolyte shell using a layer by layer deposition technique. The lipid vesicles were characterized by dynamic light scattering, cryo-transmission electron microscopy and atomic force microscopy. Polyelectrolyte coated-liposomes were highly stable as they showed no significant membrane disruption or leakage of encapsulated contents in the presence of detergent Triton TX100 [81].

\section{Multiple responsive-matrices in drug delivery}

Substantial benefits may be gained from the development of polymeric macromolecules that are responsive to small environmental changes and consequently elicit a response. Despite the many advances that have been accomplished, the field of stimuli-responsive biomaterials still faces many challenges. Most of the "smart" materials that have been investigated are primarily focused on a single type of stimulus. Developing a material that is responsive to more than one stimulus may combine the delivery of a drug with other capabilities such as detection, imaging, or feedback. Attention has been focused on materials that respond to more than one stimulus (Table 2).

\section{Temperature- and pH-responsive matrices}

Temperature- and $\mathrm{pH}$-responsive matrices have been extensively studied in drug delivery because these two parameters often deviate from the norm in diseased tissue. Both environmental changes offer the ability for self-regulated control over the delivery of a drug, avoiding the need for external stimuli. Poly $(N$-isopropylacrylamide-co-methacrylic acid) and PNIPAm are wellestablished thermo-responsive polymers [6,38,82-94]. These polymers may be combined with $\mathrm{pH}$-responsive polymers, like AA and its alkyl esters such as MAA
$[6,82,85,94,95]$. Zhang et al. prepared temperature and $\mathrm{pH}$-responsive nanoparticles from combinations of PNIPAm and MAA at different molar ratios [82]. The relative permeability of the nanoparticles increased significantly when the temperature was increased from $37^{\circ} \mathrm{C}$ to $43^{\circ} \mathrm{C}$ and when the $\mathrm{pH}$ decreased from 6 to 4 . Nanoparticles encapsulating vitamin $\mathrm{B}_{12}$ exhibited a partition coefficient that decreased from 0.8 to 0.3 with increasing temperature and decreased from 0.8 to 0.6 with decreasing $\mathrm{pH}$. Gu et al. prepared PNIPAm-co-AA hydrogels with hollow "cages" [6]. They showed that isoniazid (INH), an antitubercular drug, was located inside the cavity of the gel "cages" and also within the shell. The "cages," which were synthesized by $\mathrm{SiO}_{2}$-templated polymerization, had a silica core that was subsequently etched away by hydrofluoric acid leaving a hollow interior. The hydrodynamic diameter of the hydrogel "cages" decreased from $367 \mathrm{~nm}$ to $200 \mathrm{~nm}$ with increasing temperature and decreasing $\mathrm{pH}$. Salehi et al. synthesized an injectable hydrogel system composed of PNIPAm, acrylamide (AAm), and vinyl pyrrolidone (VP) to encapsulate naltrexone, an opiate receptor antagonist [94]. The swelling ratios of the gel increased when the $\mathrm{pH}$ decreased from 8.5 to 7.4 and decreased when the temperature increased from $25^{\circ} \mathrm{C}$ to $37^{\circ} \mathrm{C}$. They also performed in vitro release studies where a low burst effect and a slow release profile of naltrexone was observed over the course of 28 days.

In addition to PNIPAm, other temperature-responsive polymers have been investigated in dual-responsive drug delivery systems [41,96-100]. Moon et al. prepared and characterized amphiphilic, $\mathrm{pH}$ - and temperature-responsive polyaspartamide derivatives, which formed micelles with an average diameter of $100 \mathrm{~nm}$ at $25^{\circ} \mathrm{C}$ [41]. A solgel transition was observed when the temperature was increased from $15^{\circ} \mathrm{C}$ to $25^{\circ} \mathrm{C}$ and when the $\mathrm{pH}$ was increased from 6 to 10 . Ding et al. fabricated injectable hydrogels based on glycol chitosan and benzaldehydecapped poly(ethylene glycol)-block-poly(propylene glycol)-block-poly(ethylene glycol) (PEO-PPO-PEO) [98]. In vivo tests using a rat model demonstrated that the hydrogel underwent a sol-gel transition at physiological conditions. These hydrogels have the ability to encapsulate both hydrophilic and hydrophobic drugs and can control the release profile by varying temperature or $\mathrm{pH}$.

\section{Light- and $\mathrm{pH}$ - or temperature-responsive matrices}

Light-responsive materials are combined with a secondary stimulus such as temperature or $\mathrm{pH}$ to increase control over drug release. Light responsiveness is usually introduced to a temperature or $\mathrm{pH}$-sensitive material by conjugating a photo-reactive moiety [95]. Jochum et al. synthesized a thermo- and light-responsive polyacrylamide copolymer having salicylideneaniline 
Table 2 Multiple stimuli-sensitive drug delivery

\begin{tabular}{|c|c|c|c|}
\hline Stimuli & Carrier type & Payload & Reference \\
\hline \multirow[t]{3}{*}{ Temperature/pH } & PNIPAm/MAA & Vitamin $B_{12}$ & {$[82]$} \\
\hline & PNIPAm/AA & Isoniazid & {$[6]$} \\
\hline & PNIPAm/AAm/NP & Naltrexone & [94] \\
\hline \multirow{2}{*}{$\begin{array}{l}\text { Light/pH or light/ } \\
\text { temperature }\end{array}$} & Polyacrylamide/Salicylideneaniline & None reported & [101] \\
\hline & $\mathrm{PSS} / \mathrm{PAH} / \mathrm{Au}$ & FITC-dextran & {$[58]$} \\
\hline \multirow{3}{*}{$\begin{array}{l}\text { Magnetic/temperature or } \\
\text { magnetic/pH }\end{array}$} & $\mathrm{PEO} / \mathrm{PPO} / \mathrm{PEO} / \mathrm{Fe}_{2} \mathrm{O}_{3}$ & Ibuprofen and Eosin $Y$ & [102] \\
\hline & $\mathrm{PNIPAm} / \gamma-\mathrm{Fe}_{2} \mathrm{O}_{3} / \mathrm{SiO}_{2}$ & None reported & {$[105]$} \\
\hline & $\begin{array}{l}\text { MPEG-b-PDEAEMA-b-PGMA, MPEG-b-PDMAEMA-b-PGMA, PDEAEMA-b-PGMA } \\
\text { and MPEG-b-PGMA/Fe } \mathrm{O}_{4}\end{array}$ & $\begin{array}{l}\text { Chlorambucil and } \\
\text { indomethacin }\end{array}$ & [109] \\
\hline
\end{tabular}

as a photo-sensitive group [101]. Salicilideneaniline isomerizes from the enol to keto form and changes its dipole moment upon exposure to UV light. To synthesize the polymer, the authors performed a double polymer analogous reaction of poly(pentafluorophenyl acrylate) (PPFPA) and varied the molar composition of salicylideneaniline from 1 to $15 \mathrm{~mol} \%$.

Light- and pH-responsive materials have also been investigated. Angelatos et al. designed light- and $\mathrm{pH}-$ responsive polyelectrolyte/gold nanoparticle microcapsules via the layer by layer colloid-templating method [58]. Microcapsules were prepared by depositing the electrolytes poly(sodium 4-styrenesulfonate) (PSS) and poly(allylamine hydrochloride) (PAH) in a layer by layer fashion onto a template of melamine formaldehyde (MF) microparticles. The MF core was subsequently etched away with hydrochloric acid, and gold nanoparticles were introduced into the microcapsule shell. Fluorescein isothiocyanate (FITC)-dextran was encapsulated and was shown to be released after a decrease in $\mathrm{pH}$ and upon irradiation of $10 \mathrm{~ns}$ pulses of light at $1064 \mathrm{~nm}$.

Magnetic- and $\mathrm{pH}$ - or temperature-responsive matrices Magnetic fields can be remotely applied to localize drug carriers and to induce a temperature change. There have not been an extensive number of studies focusing on magnetic- and temperature-responsive materials, but this area has received increasing attention within the last few years [102-106]. Luo et al. prepared microspheres by encapsulating silica-coated superparamagnetic magnetite nanoparticle clusters with a crosslinked PNIPAm shell [105]. The microspheres exhibited a temperature-dependent swelling ratio; the hydrodynamic diameter decreased from $750 \mathrm{~nm}$ to $500 \mathrm{~nm}$ when the temperature increased from $20^{\circ} \mathrm{C}$ to $60^{\circ} \mathrm{C}$. Additionally, the microspheres had greater magnetic responsivity at temperatures higher than the volume phase transition temperature due to the decrease in size at higher temperatures. A faster separation-redispersion behavior of the microspheres was observed at $60^{\circ} \mathrm{C}$, above the volume phase transition temperature, compared to that at $25^{\circ} \mathrm{C}$. In another study, a different temperatureresponsive material, poly(ethyleneimine)-modified poly (ethylene oxide)-poly(propylene oxide)-poly(ethylene oxide) (PEO-PPO-PEO) block copolymer, was used instead of PNIPAm to coat iron oxide nanoparticles [102]. The nanoparticle hydrodynamic diameter decreased from 45 to $25 \mathrm{~nm}$ when the temperature increased from $20^{\circ} \mathrm{C}$ to $35^{\circ} \mathrm{C}$. One of the most attractive features of this drug delivery system is the ability to reversibly control the payload release by changing the PEO-PPO-PEO polymer shell conformation. The polymer shell acts as a gate; it is in an extended conformation at room temperature but changes to a coiled conformation upon heating to $37^{\circ} \mathrm{C}$. In vitro release of hydrophobic and hydrophilic model drugs was achieved by switching the temperature from $37^{\circ} \mathrm{C}$ to $20^{\circ} \mathrm{C}$. In addition, the nanoparticles showed good biocompatibility and effective nerve regeneration when loaded with a ganglioside in a spinal cord injury rat model.

Magnetic- and $\mathrm{pH}$-responsive materials have also been investigated [107-110]. Superparamagnetic $\mathrm{Fe}_{3} \mathrm{O}_{4}$ nanoparticles were coated with different $\mathrm{pH}$-responsive block copolymers [109]. Four different block copolymers, methoxypoly(ethylene glycol)-b- (N,N-diethylamino) ethyl methacrylate-b-poly(glycidyl methacrylate) (MPEG-b-PDEAEMA-b-PGMA), methoxypoly(ethylene glycol)-b-(N,N-diethylamino)methyl methacrylate-b-poly (glycidyl methacrylate) (MPEG-b-PDMAEMA-bPGMA), PDEAEMA-b-PGMA and MPEG-b-PGMA, were synthesized. The block copolymers were conjugated to the surface of $\mathrm{Fe}_{3} \mathrm{O}_{4}$ nanoparticles stabilized with $\mathrm{HClO}_{4}$ via a ligand exchange method. The authors performed drug release studies with MPEG-bPDEAEMA-b-PGMA-Fe $\mathrm{O}_{4}$ and MPEG-b-PDMAEMAb-PGMA- $\mathrm{Fe}_{3} \mathrm{O}_{4}$ nanocarriers encapsulating chlorambucil (CLB), an anti-cancer agent, and indomethacin (IND), an anti-inflammatory agent. Their results showed 
that upon a decrease in $\mathrm{pH}$ (below the $p \mathrm{~K}_{\mathrm{a}}$ of each drug), the percentage of drug release increased up to $90 \%$ for CLB and 70\% for IND. At pH 7.4 the percent of drug release for both IND and CLB was approximately $25 \%$.

\section{Concluding remarks}

The ability to alter the biodistribution of a drug by modulating its release profile through the use of smart polymers could transform drug delivery from passive controlled release to active stimuli-regulated delivery. Altering the drug biodistribution has the ability to reduce toxicity and side effects while improving therapeutic outcomes due to the ability to deliver higher doses of drug to the site of interest. The stimuli-responsive polymers reviewed here serve to provide a snapshot of the utility and complexity of polymers that can sense, process, and respond to stimuli in modulating the release of a drug. Stimuli-responsive drug delivery vehicles come in the form of polymersomes [111,112], liposomes [113-115], micelles [116-118], and dendrimers $[119,120]$. All of these systems aim to deliver an effective dose of drug at a specific time and place.

Despite many advances, there are still numerous challenges and opportunities that exist to translate responsive polymers from the laboratory the clinic. There is a need to develop polymers with greater sensitivity to a more diverse range of stimuli. In terms of biochemical signals or biomarkers, this is usually in the range of nano to picomolar concentrations [121]. This may require both a highly sensitive sensing mechanism and/or an amplification system to elicit a response from the polymer. In terms of the physical microenvironment, there are only minor differences in $\mathrm{pH}$ and temperature between diseased and normal tissues. Therefore, smart polymers must be able to accurately sense the changes in their surroundings to target drug release.

There is also a significant opportunity for smart polymers to respond to multiple stimuli. Hybrid polymers created in this manner will offer more parameters to tune drug delivery, which may be necessary for more complex and dynamic environments. It is worth noting that in addition to drug delivery applications, smart polymers in general have broad applications in tissue engineering and regenerative medicine (e.g. as injectable systems for delivery of cells or self-regulating scaffolds for cell growth or infiltration), and in actuators (e.g. as smart valves and coating in microfluidics or shape memory devices). Given the continuous development of new responsive polymer compositions, we expect increasingly elaborate and versatile drug carriers to be introduced in the future.

\section{Acknowledgements}

The authors gratefully acknowledge research support from the MRSEC program of the National Science Foundation under Award Number DMR0820484. This work was performed in part at the Center for Nanoscale Systems (CNS), a member of the National Nanotechnology Infrastructure Network (NNIN), which is supported by the National Science Foundation under NSF award no. ECS-0335765. CNS is part of the Faculty of Arts and Sciences at Harvard University.

\section{Authors' contributions}

JY performed the experiments of transmission electron microscope (TEM), paclitaxel release study, and drafted the manuscript. JY, DA, and GY wrote the manuscript. DTA is responsible for the overall content. All authors read and approved the final manuscript.

\section{Competing interests}

The authors declare that they have no competing interests.

Received: 27 August 2010 Accepted: 29 November 2010 Published: 29 November 2010

\section{References}

1. Gemeinhart RA, Chen J, Park H, Park K: pH-sensitivity of fast responsive superporous hydrogels. J Biomater Sci Polym Ed 2000, 11:1371-1380.

2. Gemeinhart RA, Park H, Park K: Effect of compression on fast swelling of poly(acrylamide-co-acrylic acid) superporous hydrogels. J Biomed Mater Res 2001, 55:54-62.

3. You JO, Auguste DT: Feedback-regulated paclitaxel delivery based on poly(N,N-dimethylaminoethyl methacrylate-co-2-hydroxyethyl methacrylate) nanoparticles. Biomaterials 2008, 29:1950-1957.

4. Jhaveri SJ, Hynd MR, Dowell-Mesfin N, Turner JN, Shain W, Ober CK: Release of nerve growth factor from HEMA hydrogel-coated substrates and its effect on the differentiation of neural cells. Biomacromolecules 2009, 10:174-183.

5. Galaev IY, Mattiasson B: 'Smart' polymers and what they could do in biotechnology and medicine. Trends Biotechnol 1999, 17:335-340.

6. Gu JX, Xia F, Wu Y, Qu XZ, Yang ZZ, Jiang L: Programmable delivery of hydrophilic drug using dually responsive hydrogel cages. J Controlled Release 2007, 117:396-402.

7. Shim WS, Kim JH, Kim K, Kim YS, Park RW, Kim IS, Kwon IC, Lee DS: pHand temperature-sensitive, injectable, biodegradable block copolymer hydrogels as carriers for paclitaxel. Int J Pharm 2007, 331:11-18.

8. Dufresne MH, Le Garrec D, Sant V, Leroux JC, Ranger M: Preparation and characterization of water-soluble $\mathrm{pH}$-sensitive nanocarriers for drug delivery. Int J Pharm 2004, 277:81-90.

9. Pichot $C$, Taniguchi T, Delair T, Elaissari A: Functionalized thermosensitive latex particles: Useful tools for diagnostics. J Disper Sci Technol 2003, 24:423-437.

10. Mart RJ, Osborne RD, Stevens MM, Ulijn RV: Peptide-based stimuliresponsive biomaterials. Soft Matter 2006, 2:822-835.

11. Luzinov I, Minko S, Tsukruk W: Responsive brush layers: from tailored gradients to reversibly assembled nanoparticles. Soft Matter 2008, 4:714-725.

12. Motornov M, Minko S, Eichhorn K, Nitschke M, Simon F, Stamm M: Reversible tuning of wetting behavior of polymer surface with responsive polymer brushes. Langmuir 2003, 19:8077-8085.

13. Alarcon $\mathrm{CDH}$, Pennadam S, Alexander C: Stimuli responsive polymers for biomedical applications. Chem Soc Rev 2005, 34:276-285.

14. Beebe DJ, Moore JS, Bauer JM, Yu Q, Liu RH, Devadoss C, Jo BH: Functional hydrogel structures for autonomous flow control inside microfluidic channels. Nature 2000, 404:588-590.

15. Kuhn W, Hargitay B, Katchalsky A, Eisenberg H: Reversible dilation and contraction by changing the state of ionization of high-polymer acid networks. Nature 1950, 165:514-516.

16. Ramkissoon-Ganorkar C, Liu F, Baudys M, Kim SW: Modulating insulinrelease profile from $\mathrm{pH}$ thermosensitive polymeric beads through polymer molecular weight. J Controlled Release 1999, 59:287-298.

17. Suedee $R$, Jantarat C, Lindner W, Viernstein H, Songkro S, Srichana T: Development of a $\mathrm{pH}$-responsive drug delivery system for enantioselective-controlled delivery of racemic drugs. J Controlled Release 2010, 142:122-131. 
18. Du JZ, Tang YP, Lewis AL, Armes SP: pH-sensitive vesicles based on a biocompatible zwitterionic diblock copolymer. J Am Chem Soc 2005, 127:17982-17983.

19. Lomas H, Massignani M, Abdullah KA, Canton I, Lo Presti C, MacNeil S, Du J, Blanazs A, Madsen J, Armes SP, Lewis AL, Battaglia G: Non-cytotoxic polymer vesicles for rapid and efficient intracellular delivery. Faraday Discussions 2008, 139:143-159.

20. Griset AP, Walpole J, Liu R, Gaffey A, Colson YL, Grinstaff MW: Expansile nanoparticles: Synthesis, characterization, and in vivo efficacy of an acidresponsive Polymeric drug delivery system. J Am Chem Soc 2009, 131:2469-2471

21. Tan BH, Tam KC, Lam YC, Tan CB: Microstructure and rheology of stimuliresponsive nanocolloidal systems - Effect of ionic strength. Langmuir 2004, 20:11380-11386.

22. Meyers SR, Kenan DJ, Grinstaff MW: Enzymatic release of a surfaceadsorbed RGD therapeutic from a cleavable peptide anchor. Chemmedchem 2008, 3:1645-1648.

23. Lomadze N, Schneider HM: Ternary complex formation inducing large expansions of chemomechanical polymers by metal chelators, aminoacids and peptides as effectors. Tetrahedron Lett 2005, 46:751-754.

24. Zrinyi M: Intelligent polymer gels controlled by magnetic fields. Colloid Polym Sci 2000, 278:98-103.

25. Harris KD, Cuypers R, Scheibe P, van Oosten CL, Bastiaansen CWM, Lub J, Broer DJ: Large amplitude light-induced motion in high elastic modulus polymer actuators. J Mater Chem 2005, 15:5043-5048.

26. Juodkazis S, Mukai N, Wakaki R, Yamaguchi A, Matsuo S, Misawa H: Reversible phase transitions in polymer gels induced by radiation forces. Nature 2000, 408:178-181.

27. Kwok CS, Mourad PD, Crum LA, Ratner BD: Self-assembled molecular structures as ultrasonically-responsive barrier membranes for pulsatile drug delivery. J Biomed Mater Res 2001, 57:151-164.

28. Lowman AM, Morishita M, Kajita M, Nagai T, Peppas NA: Oral delivery of insulin using pH-responsive complexation gels. J Pharm Sci 1999, 88:933-937.

29. Dai JD, Nagai $T$, Wang $X Q$, Zhang $T$, Meng $M$, Zhang Q: $p H$-sensitive nanoparticles for improving the oral bioavailability of cyclosporine A. Int J Pharm 2004, 280:229-240.

30. Lim DW, Yeom Yl, Park TG: Poly(DMAEMA-NVP)-b-PEG-galactose as gene delivery vector for hepatocytes. Bioconjug Chem 2000, 11:688-695.

31. Napoli A, Boerakker MJ, Tirelli N, Nolte RJM, Sommerdijk NAJM, Hubbell JA Glucose-oxidase based self-destructing polymeric vesicles. Langmuir 2004, 20:3487-3491.

32. Schmaljohann D: Thermo- and $\mathrm{pH}$-responsive polymers in drug delivery. Adv Drug Deliv Rev 2006, 58:1655-1670.

33. Traitel $T$, Cohen $Y$, Kost J: Characterization of glucose-sensitive insulin release systems in simulated in vivo conditions. Biomaterials 2000, 21:1679-1687.

34. Herber S, Eijkel J, Olthuis W, Bergveld P, van den Berg A: Study of chemically induced pressure generation of hydrogels under isochoric conditions using a microfabricated device. J Chem Phys 2004, 121:2746-2751

35. Guice KB, Loo YL: Azeotropic atom transfer radical polymerization of hydroxyethyl methacrylate and (dimethylamino)ethyl methacrylate statistical copolymers and block copolymers with polystyrene. Macromolecules 2006, 39:2474-2480.

36. Liu SQ, Tong YW, Yang YY: Thermally sensitive micelles self-assembled from poly(N-isopropylacrylamide-co-N,N-dimethylacrylamide)-b-poly(D,Llactide-co-glycolide) for controlled delivers of paclitaxel. Mol Biosyst 2005, 1:158-165

37. Budhlall BM, Marquez M, Velev OD: Microwave, photo- and thermally responsive PNIPAm-gold nanoparticle microgels. Langmuir 2008, 24:11959-11966.

38. Shi J, Alves NM, Mano JF: Chitosan coated alginate beads containing poly ( $\mathrm{N}$-isopropylacrylamide) for dual-stimuli-responsive drug release. $J$ Biomed Mater Res B 2008, 84B:595-603.

39. You JO, Park SB, Park HY, Haam S, Chung CH, Kim WS: Preparation of regular sized $\mathrm{Ca}$-alginate microspheres using membrane emulsification method. J Microencapsul 2001, 18:521-532.

40. You JO, Peng CA: Phagocytosis-mediated retroviral transduction: cointernatization of deactivated retrovirus and calcium-alginate microspheres by macrophages. J Gene Med 2005, 7:398-406.
41. Moon JR, Park YH, Kim JH: Synthesis and characterization of novel thermo- and $\mathrm{pH}$-responsive copolymers based on amphiphilic polyaspartamides. J Appl Polym Sci 2009, 111:998-1004.

42. Felt $O$, Buri $P$, Gurny R: Chitosan: $A$ unique polysaccharide for drug delivery. Drug Dev Ind Pharm 1998, 24:979-993.

43. Pourjavadi A, Barzegar S, Zeidabadi F: Synthesis and properties of biodegradable hydrogels of kappa-carrageenan grafted acrylic acid-co-2acrylamido-2-methylpropanesulfonic acid as candidates for drug delivery systems. React Funct Polym 2007, 67:644-654.

44. Jarvinen K, Akerman S, Svarfvar B, Tarvainen T, Viinikka P, Paronen P: Drug release from $\mathrm{pH}$ and ionic strength responsive poly(acrylic acid) grafted poly(vinylidenefluoride) membrane bags in vitro. Pharm Res 1998, 15:802-805.

45. Jones MC, Ranger M, Leroux JC: $\mathrm{pH}$-sensitive unimolecular polymeric micelles: Synthesis of a novel drug carrier. Bioconjug Chem 2003, 14:774-781.

46. Heffernan MJ, Murthy N: Polyketal nanoparticles: a new $\mathrm{pH}$-sensitive biodegradable drug delivery vehicle. Bioconjug Chem 2005, 16:1340-1342.

47. van de Wetering P, Moret EE, Schuurmans-Nieuwenbroek NME, van Steenbergen MJ, Hennink WE: Structure-activity relationships of watersoluble cationic methacrylate/methacrylamide polymers for nonviral gene delivery. Bioconjug Chem 1999, 10:589-597.

48. Kavetskii RE, Osinskii SP, Bubnovskaya LN: Activation of glycolysis in tumor-tissue by inorganic-phosphate at low pH values. Bull Exp Biol Med 1979, 87:277-278.

49. You JO, Auguste DT: Nanocarrier cross-linking density and $\mathrm{pH}$ sensitivity regulate intracellular gene transfer. Nano Lett 2009, 9:4467-4473.

50. You JO, Auguste DT: The effect of swelling and cationic character on gene transfection by $\mathrm{pH}$-sensitive nanocarriers. Biomaterials 2010, 31:6859-6866

51. Auguste DT, Armes SP, Brzezinska KR, Deming TJ, Kohn J, Prud'homme RK $\mathrm{pH}$ triggered release of protective poly(ethylene glycol)-b-polycation copolymers from liposomes. Biomaterials 2006, 27:2599-2608.

52. Liang $E$, Hughes JA: Membrane fusion and rupture in liposomes: Effect of biodegradable pH-sensitive surfactants. J Membr Biol 1998, 166:37-49.

53. Wilschut J, Hoekstra D: Membrane-fusion - from liposomes to biologicalmembranes. Trends Biochem Sci 1984, 9:479-483.

54. Needham D, Anyarambhatla G, Kong G, Dewhirst MW: A new temperaturesensitive liposome for use with mild hyperthermia: Characterization and testing in a human tumor xenograft model. Cancer Res 2000, 60:1197-1201.

55. Sutton D, Nasongkla N, Blanco E, Gao JM: Functionalized micellar systems for cancer targeted drug delivery. Pharm Res 2007, 24:1029-1046.

56. Wang MZ, Fang Y, Hu DD: Preparation and properties of chitosan-poly(Nisopropylacrylamide) full-IPN hydrogels. React Funct Polym 2001, 48:215-221.

57. De P, Gondi SR, Sumerlin BS: Folate-conjugated thermoresponsive block copolymers: Highly efficient conjugation and solution self-assembly. Biomacromolecules 2008, 9:1064-1070.

58. Angelatos AS, Radt B, Caruso F: Light-responsive polyelectrolyte/gold nanoparticle microcapsules. J Phys Chem B 2005, 109:3071-3076.

59. Alvarez-Lorenzo C, Bromberg L, Concheiro A: Light-sensitive intelligent drug delivery systems. Photochem Photobiol 2009, 85:848-860.

60. Suzuki A, Tanaka T: Phase-transition in polymer gels induced by visiblelight. Nature 1990, 346:345-347.

61. Vivero-Escoto JL, Slowing II, Wu CW, Lin VS: Photoinduced intracellular controlled release drug delivery in human cells by gold-capped mesoporous silica nanosphere. J Am Chem Soc 2009, 131:3462-3463.

62. Klaikherd ANC, Thayumanavan S: Multi-stimuli sensitive amphiphilic block copolymer assemblies. J Am Chem Soc 2009, 131:4830-4838.

63. Fomina N, McFearin C, Sermsakdi M, Edigin O, Almutairi A: UV and near-IR triggered release from polymeric nanoparticles. J Am Chem Soc 2010, 132:9540-9542.

64. Husseini GA, de la Rosa MAD, Richardson ES, Christensen DA, Pitt WG: The role of cavitation in acoustically activated drug delivery. J Controlled Release 2005, 107:253-261.

65. Husseini GA, Pitt WG: Ultrasonic-activated micellar drug delivery for cancer treatment. J Pharm Sci 2009, 98:795-811.

66. Pruitt JD, Pitt WG: Sequestration and ultrasound-induced release of doxorubicin from stabilized Pluronic P105 micelles. Drug Deliv 2002, 9:253-258 
67. Lin HY, Thomas JL: Factors affecting responsivity of unilamellar liposomes to $20 \mathrm{kHz}$ ultrasound. Langmuir 2004, 20:6100-6106.

68. Ferrara K, Pollard R, Borden M: Ultrasound microbubble contrast agents: Fundamentals and application to gene and drug delivery. Annu Rev Biomed Eng 2007, 9:415-447.

69. Hassan CM, Doyle FJ, Peppas NA: Dynamic behavior of glucoseresponsive poly(methacrylic acid-g-ethylene glycol) hydrogels. Macromolecules 1997, 30:6166-6173.

70. Ishihara K, Matsui K: Glucose-responsive insulin release from polymer capsule. J Polym Sci C 1986, 24:413-417.

71. Kataoka K, Miyazaki H, Okano T, Sakurai Y: Sensitive glucose-induced change of the lower critical solution temperature of poly $[\mathrm{N}, \mathrm{N}-$ dimethylacrylamide-co-3-(acrylamido)phenyl-boronic acid] in physiological saline. Macromolecules 1994, 27:1061-1062.

72. Kataoka K, Miyazaki H, Bunya M, Okano T, Sakurai Y: Totally synthetic polymer gels responding to external glucose concentration: Their preparation and application to on-off regulation of insulin release. J Am Chem Soc 1998, 120:12694-12695.

73. Miyata T, Jikihara A, Nakamae K, Hoffman AS: Preparation of reversibly glucose-responsive hydrogels by covalent immobilization of lectin in polymer networks having pendant glucose. J Biomater Sci Polym Ed 2004, 15:1085-1098.

74. Zhang R, Tang M, Bowyer A, Eisenthal R, Hubble J: Synthesis and characterization of a D-glucose sensitive hydrogel based on CM-dextran and concanavalin A. React Funct Polym 2006, 66:757-767.

75. Aimetti AA, Tibbitt MW, Anseth KS: Human neutrophil elastase responsive delivery from poly(ethylene glycol) hydrogels. Biomacromolecules 2009, 10:1484-1489.

76. Sakiyama-Elbert SE, Panitch A, Hubbell JA: Development of growth factor fusion proteins for cell-triggered drug delivery. FASEB J 2001, 15:1300-1302.

77. Pedersen PJ, Adolph SK, Subramanian AK, Arouri A, Andresen TL, Mouritsen OG, Madsen R, Madsen MW, Peters GH, Clausen MH: Liposomal formulation of retinoids designed for enzyme triggered release. J Med Chem 2010, 53:3782-3792.

78. Arias $\mathrm{JL}$, Reddy $\mathrm{LH}$, Couvreur P: Magnetoresponsive squalenoyl gemcitabine composite nanoparticles for cancer active targeting. Langmuir 2008, 24:7512-7519.

79. Liu HL, Hua MY, Yang HW, Huang CY, Chu PC, Wu JS, Tseng IC, Wang JJ, Yen TC, Chen PY, Wei KC: Magnetic resonance monitoring of focused ultrasound/magnetic nanoparticle targeting delivery of therapeutic agents to the brain. Proc Natl Acad Sci USA 2010, 107:15205-15210.

80. Chorny M, Fishbein I, Yellen BB, Alferiev IS, Bakay M, Ganta S, Adamo R, Amiji M, Friedman G, Levy RJ: Targeting stents with local delivery of paclitaxel-loaded magnetic nanoparticles using uniform fields. Proc Nat Acad Sci USA 2010, 107:8346-8351.

81. Gomes JFPD, Rank A, Kronenberger A, Fritz J, Winterhalter M, Ramaye Y: Polyelectrolyte-coated unilamellar nanometer-sized magnetic liposomes. Langmuir 2009, 25:6793-6799.

82. Zhang $\mathrm{K}, \mathrm{Wu} \mathrm{XY}$ : Temperature and $\mathrm{pH}$-responsive polymeric composite membranes for controlled delivery of proteins and peptides. Biomaterials 2004, 25:5281-5291.

83. Shi J, Alves NM, Mano JF: Drug release of $\mathrm{pH} /$ temperature-responsive calcium alginate/poly(N-isopropylacrylamide) semi-IPN beads. Macromo Biosci 2006, 6:358-363.

84. Wei H, Zhang XZ, Cheng H, Chen WQ, Cheng SX, Zhuo RX: Self-assembled thermo- and $\mathrm{pH}$-responsive micelles of poly(10-undecenoic acid-b- $\mathrm{N}$ isopropylacrylamide) for drug delivery. J Controlled Release 2006, 116:266-274.

85. Yin X, Hoffman AS, Stayton PS: Poly(N-isopropylacrylamide-copropylacrylic acid) copolymers that respond sharply to temperature and pH. Biomacromolecules 2006, 7:1381-1385.

86. Jiang XZ, Ge ZS, Xu J, Liu H, Liu SY: Fabrication of multiresponsive shell cross-linked micelles possessing $\mathrm{pH}$-controllable core swellability and thermo-tunable corona permeability. Biomacromolecules 2007, 8:3184-3192

87. Wang $\mathrm{D}$, Chen $\mathrm{LW}$ : Temperature and $\mathrm{pH}$-responsive single-walled carbon nanotube dispersions. Nano Lett 2007, 7:1480-1484.

88. Zhang $L Y$, Guo $R$, Yang $M$, Jiang $X Q$, Liu BR: Thermo and $p H$ dualresponsive nanoparticles for anti-cancer drug delivery. Adv Mater 2007, 19:2988-2992.
89. Morinloto N, Qiu XP, Winnik FM, Akiyoshi K: Dual stimuli-responsive nanogels by self-assembly of polysaccharides lightly grafted with thiolterminated poly(N-isopropylacrylamide) chains. Macromolecules 2008, 41:5985-5987.

90. Shi J, Liu LH, Sun XM, Cao SK, Mano JF: Biomineralized polysaccharide beads for dual-stimuli-responsive drug delivery. Macromol Biosci 2008, 8:260-267.

91. Chang C, Wei H, Feng J, Wang ZC, Wu XJ, Wu DQ, Cheng SX, Zhang XZ, Zhuo RX: Temperature and $\mathrm{pH}$ double responsive hybrid cross-linked micelles based on P(NIPAAm-co-MPMA)-b-P(DEA): RAFT synthesis and "schizophrenic" micellization. Macromolecules 2009, 42:4838-4844.

92. Fundueanu G, Constantin M, Stanciu C, Theodoridis G, Ascenzi P: pH- and temperature-sensitive polymeric microspheres for drug delivery: the dissolution of copolymers modulates drug release. J Mater Sci-Mater Med 2009, 20:2465-2475.

93. Liu YH, Cao XH, Luo MB, Le ZG, Xu WY: Self-assembled micellar nanoparticles of a novel star copolymer for thermo and $\mathrm{pH}$ dualresponsive drug release. J Colloid Interf Sci 2009, 329:244-252.

94. Salehi R, Arsalani N, Davaran S, Entezami AA: Synthesis and characterization of thermosensitive and $\mathrm{pH}$-sensitive poly $(\mathrm{N}$ isopropylacrylamide-acrylamide-vinylpyrrolidone) for use in controlled release of naltrexone. J Biomed Mater Res A 2009, 89A:919-928.

95. Li YY, Dong HQ, Wang K, Shi DL, Zhang XZ, Zhuo RX: Stimulus-responsive polymeric nanoparticles for biomedical applications. Science ChinaChemistry 2010, 53:447-457.

96. Guo BL, Yuan JF, Yao L, Gao QY: Preparation and release profiles of pH/ temperature-responsive carboxymethyl chitosan/P(2-(dimethylamino) ethyl methacrylate) semi-IPN amphoteric hydrogel. Colloid Polym Sci 2007, 285:665-671.

97. Basset C, Harder C, Vidaud C, Dejugnat C: Design of double stimuliresponsive polyelectrolyte microcontainers for protein soft encapsulation. Biomacromolecules 2010, 11:806-814.

98. Ding CX, Zhao LL, Liu FY, Cheng J, Gu JX, Shan-Dan, Liu CY, Qu XZ, Yang ZZ: Dually responsive injectable hydrogel prepared by in situ cross-linking of glycol chitosan and benzaldehyde-capped PEO-PPOPEO. Biomacromolecules 2010, 11:1043-1051.

99. Gao M, Jia XR, Li Y, Liang DH, Wei Y: Synthesis and thermo-/pH-dual responsive properties of poly(amidoamine) dendronized poly(2hydroxyethyl) methacrylate. Macromolecules 2010, 43:4314-4323.

100. Liu X, Ni PH, He JL, Zhang MZ: Synthesis and micellization of pH/ Temperature-responsive double-hydrophilic diblock copolymers polyphosphoester-block-poly[2-(dimethylamino)ethyl methacrylate] prepared via ROP and ATRP. Macromolecules 2010, 43:4771-4781.

101. Jochum FD, Theato P: Temperature- and light-responsive polyacrylamides prepared by a double polymer analogous reaction of activated ester polymers. Macromolecules 2009, 42:5941-5945.

102. Chen S, Li Y, Guo C, Wang J, Ma JH, Liang XF, Yang LR, Liu HZ: Temperatureresponsive magnetite/PEO-PPO-PEO block copolymer nanoparticles for controlled drug targeting delivery. Langmuir 2007, 23:12669-12676.

103. Zhang JL, Srivastava RS, Misra RDK: Core-shell magnetite nanoparticles surface encapsulated with smart stimuli-responsive polymer: Synthesis, characterization, and LCST of viable drug-targeting delivery system. Langmuir 2007, 23:6342-6351.

104. Brazel CS: Magnetothermally-responsive nanomaterials: combining magnetic nanostructures and thermally-sensitive polymers for triggered drug release. Pharm Res 2009, 26:644-656.

105. Luo B, Song XJ, Zhang F, Xia A, Yang WL, Hu JH, Wang CC: Multifunctional thermosensitive composite microspheres with high magnetic susceptibility based on magnetite colloidal nanoparticle clusters. Langmuir 2010, 26:1674-1679.

106. Pradhan P, Giri J, Rieken F, Koch C, Mykhaylyk O, Doblinger M, Banerjee R, Bahadur D, Plank C: Targeted temperature sensitive magnetic liposomes for thermo-chemotherapy. J Controlled Release 2010, 142:108-121.

107. Chatterjee J, Haik Y, Chen CJ: pH-reversible magnetic gel with a biodegradable polymer. J Appl Polym Sci 2004, 91:3337-3341.

108. Li LL, Chen D, Zhang YQ, Deng ZT, Ren XL, Meng XW, Tang FQ, Ren J, Zhang $L$ : Magnetic and fluorescent multifunctional chitosan nanoparticles as a smart drug delivery system. Nanotechnology 2007, 18:1-6.

109. Guo M, Yan Y, Liu XZ, Yan HS, Liu KL, Zhang HK, Cao YJ: Multilayer nanoparticles with a magnetite core and a polycation inner shell as $\mathrm{pH}$ responsive carriers for drug delivery. Nanoscale 2010, 2:434-441. 
110. Guo M, Yan Y, Zhang HK, Yan HS, Cao YJ, Liu KL, Wan SR, Huang JS, Yue W: Magnetic and pH-responsive nanocarriers with multilayer core-shell architecture for anticancer drug delivery. J Mater Chem 2008, 18:5104-5112.

111. Kim MS, Lee DS: Biodegradable and $\mathrm{pH}$-sensitive polymersome with tuning permeable membrane for drug delivery carrier. Chem Commun 2010, 46:4481-4483.

112. Chen W, Meng FH, Cheng R, Zhong ZY: pH-Sensitive degradable polymersomes for triggered release of anticancer drugs: A comparative study with micelles. J Controlled Release 2010, 142:40-46.

113. Bae Y, Jang WD, Nishiyama N, Fukushima S, Kataoka K: Multifunctional polymeric micelles with folate-mediated cancer cell targeting and $\mathrm{pH}$ triggered drug releasing properties for active intracellular drug delivery. Mol Biosyst 2005, 1:242-250.

114. Bae Y, Nishiyama N, Fukushima S, Koyama H, Yasuhiro M, Kataoka K: Preparation and biological characterization of polymeric micelle drug carriers with intracellular $\mathrm{pH}$-triggered drug release property: Tumor permeability, controlled subcellular drug distribution, and enhanced in vivo antitumor efficacy. Bioconjug Chem 2005, 16:122-130.

115. Liu SQ, Wiradharma N, Gao SJ, Tong YW, Yang YY: Bio-functional micelles self-assembled from a folate-conjugated block copolymer for targeted intracellular delivery of anticancer drugs. Biomaterials 2007, 28:1423-1433.

116. Fattal E, Couvreur P, Dubernet C: "Smart" delivery of antisense oligonucleotides by anionic pH-sensitive liposomes. Adv Drug Deliv Rev 2004, 56:931-946.

117. Ishida T, Kirchmeier MJ, Moase EH, Zalipsky S, Allen TM: Targeted delivery and triggered release of liposomal doxorubicin enhances cytotoxicity against human B lymphoma cells. Biochim Biophys Acta-Biomembr 2001, 1515:144-158.

118. Shigeta K, Kawakami S, Higuchi Y, Okuda T, Yagi H, Yamashita F, Hashida M: Novel histidine-conjugated galactosylated cationic liposomes for efficient hepatocyte-selective gene transfer in human hepatoma HepG2 cells. J Controlled Release 2007, 118:262-270.

119. Hui $\mathrm{H}$, Fan XD, Cao ZL: Thermo- and $\mathrm{pH}$-sensitive dendrimer derivatives with a shell of poly ( $\mathrm{N}, \mathrm{N}$-dimethylaminoethyl methacrylate) and study of their controlled drug release behavior. Polymer 2005, 46:9514-9522.

120. Lai PS, Lou PJ, Peng CL, Pai CL, Yen WN, Huang MY, Young TH, Shieh MJ: Doxorubicin delivery by polyamidoamine dendrimer conjugation and photochemical internalization for cancer therapy. I Controlled Release 2007, 122:39-46.

121. Stuart MAC, Huck WTS, Genzer J, Muller M, Ober C, Stamm M, Sukhorukov GB, Szleifer I, Tsukruk W, Urban M, Winnik F, Zauscher S, Luzinov I, Minko S: Emerging applications of stimuli-responsive polymer materials. Nature Mater 2010, 9:101-113.

doi:10.1186/1754-1611-4-15

Cite this article as: You et al: Bioresponsive matrices in drug delivery. Journal of Biological Engineering 2010 4:15.

\section{Submit your next manuscript to BioMed Central and take full advantage of:}

- Convenient online submission

- Thorough peer review

- No space constraints or color figure charges

- Immediate publication on acceptance

- Inclusion in PubMed, CAS, Scopus and Google Scholar

- Research which is freely available for redistribution

Submit your manuscript at www.biomedcentral.com/submit 